\title{
Contribution of shared bikes to carbon dioxide emission reduction and the economy in Beijing
}

\author{
Yijie Cao \\ University of Portsmouth \\ Dan Shen \\ University of Portsmouth
}

\begin{abstract}
In recent years, the popularity of sharing economy has been growing worldwide. Therefore, its features must be understood to adapt the economic development for the enterprises. The performance of Mobike in Beijing is used as a case in this study. Mobike is the largest shared bike company in the world and plays a prominent role in the sharing economy. Based on data obtained, online reports, and actual situations, the factors affecting the environment from shared bikes and the usage of bikes have been analyzed qualitatively and quantitatively. From the qualitative analysis, the model of the contribution of carbon dioxide emission reduction to the society has been constructed with the significant variables of registered rate, riding distance, and usage rate for shared bikes. The influence degree of each variable and their interactions are evaluated through response surface method and Minitab. The influencing extent of factors on $\mathrm{CO}_{2}$ emission reduction is in the following order: riding distance >proportion of registered users $>$ usage rate of shared bikes. The results show that shared bike plays comprehensive and positive roles for economy and environment. The study will provide a significant help for policymakers and business supervisors on development of shared bikes.
\end{abstract}

Keywords: carbon dioxide; economy; emission reduction; shared bikes.

\section{Introduction}

Shared bikes in China emerged in 2016, and its number has remarkably grown in all major cities in the country. In fact, shared bikes were even extended to other countries, such as the United States and the United Kingdom. Considering their convenience and easy payment, an increasing number of people use shared bikes. Thus, the usage of 
shared bikes notably grew in 2017. In 2018, the industry slightly grew. Given its enormous influence on Chinese society, the point of evolution of sharing economy in China began in 2017. Until the end of 2017, approximately 77 shared bike companies were in operation. Their registered users have exceeded0.4 billion, and their services have been used approximately 17 billion times. A total of 230 million bikes have been launched worldwide, with China creating a record of the highest usage of 700 million people in 1 day. Shared bikes are distributed in over 200 cities in China, where 230 million shared bikes are available for use (https://www.ithome.com/html/it/346670.htm, accessed May 20, 2018). Shared bikes have effectively stimulated the upstream and downstream industries, which represent the manufacturing and service industries, respectively. In addition, shared bikes can continue to boost the industry's endogenous motivation and create a new ecosystem. The primary structures of the shared bike industry have gradually been formed. Shared bikes also play an important role in creating a green economy in sharing economy. They not only improve the microcirculation of local traffic and reduce the emission of pollutants but also create a sustainable economic model.

As a environmental protection industry, the shared bike industry has been supported by the government and the general public. Mobike offers a way for shared bike companies to optimally allocate their bike resources, thus maximizing shared bikes' usage. Efficient placement of shared bikes can create opportunities to increase the usage rate, proportion of users, and riding distance.

This study aims to help managers and policymakers comprehensively understand the significance of shared bikes on society and the environment. Through a review and analysis of literature combined with the database from Mobike about shared bikes, some important factors and the degree of influence of shared bikes on the environment and economy have been illustrated qualitatively. Based on the abovementioned work, the model for carbon dioxide emission reduction and economic benefits has been constructed. It focuses on raising public awareness on environmental protection and motivating people to perform green and low-carbon activities. The results demonstrate the importance of shared bikes on the economy and the environment. This study will be helpful for the healthy development of shared bikes, related industrial chains, and protection of the environment. 


\subsection{Sharing economy}

Ruggles (1998) stated that one party provides surplus assets or services to another party in a compensated or unpaid manner through a third-party platform (the Internet or the mobile Internet). Sharing economy mostly depends on online platforms of information and communications technology that has been built by a third party. Transactions by individual consumers were conducted through the platform. Thus, resources and information can be shared. Hamari, Sjöklint, and Ukkonen (2016) argued that sharing economy is also called "collaborative economy," using economy, sharing the access to goods and services, or coordinating service-based community. The construction of a sharing platform through information technology ensures effective utilization of unused resources, such as services and information. Among these resources, sharing economy is closely related to information sharing. Sharing economy will accelerate the globalized distribution of companies and promote the matching capabilities between the position in the employment market and job hunter and provide numerous jobs. It can also accelerate the transformation of companies, thereby providing a new choice of social consumption.

In simple terms, the sharing economy is a consumer-to-consumer $(\mathrm{C} 2 \mathrm{C})$ business model, which involves people who share their personal resources, surplus assets, or services to other parties, such as sharing a taxi, a car, or a bike. The shared bike system can be likened to a new type of bike rental company (Xiong, 2017). Generally, regardless if its model is business-to-business, business-to-consumer, or cradle-to-cradle, the sharing economy enables the sharing of products or services. It creates economic value and innovation to reflect the benefit from sharing economy using anew network platform.

In essence, sharing economy is a leasing economy, thus narrowing the distance between the owner and the user through information sharing. Take a shared bike as an example; on the one hand, a registered user has the right to unlock the identified bike and use it as he wishes. On the other hand, bike owners have the right to collect fees from the users and repair their bikes. In the sharing economy, everyone can become producers (owners) or consumers (users).

With the gradual maturity of the third-party platform, the market will be further opened and the efficiency of use for goods will be sharply increased given the reduction of the marginal cost between the producer and the consumer. In the traditional economy, market transactions frequently require middlemen. Middlemen do not only increase the cost of transaction but also reduce efficiency. By contrast, in the sharing economy, the role of the middleman is increasingly confined given the information-sharing and third-party 
platform functions. Thus, the role of human intervention becomes minimal, and competition becomes fair. Heinrichs (2013) further argued that various idle and scattered resources can be quickly integrated by third-party online platforms. Zhou and Lo (2004) stated that the contradiction of supply and demand can be efficiently relieved by huge databases through analysis and optimization method. Such a sharing mode is helpful in overcoming the information asymmetry between "face-to-face" transactions and in significantly reducing transaction costs. Matofska (2014) expounded that the essence of sharing economy is enhancing service quality and improving the environment. Sharing economy does not only create good services but also reduces carbon emission, thereby showing the strong relationship between core subjective and responsibility of the environment.

Furthermore, Heinrichs (2013) stated that sharing economy can generate new pathways for sustainable development, which can benefit from its ability to rapidly gather scattered resources. These views provided an opportunity to re-evaluate our economy, environment, and involved energy with a long-term and sustainable viewpoint. However, Wang (2017) contended that the rapid growth of the sharing economy has current incremental and negative crowding-out effects on the traditional economy. Chen (2018, p.231-252) used Didi Taxi as an example to evaluate some impacts of the expansion of Didi on the taxi industry, in which the number of new taxis has been declining annually since 2013. In 2015, the number of taxi carriers and their running miles declined by $2.3 \%$ and $1.0 \%$ for the first time, correspondingly. Zervas, et al. (2017) conducted a key analysis of the tight competition between local hotels and Airbnb accommodations. The hotels in areas where Airbnb has been established have cut down their prices in response to the competition. Such price wars benefit the traveler but pose a threat to hotel revenues. These phenomena reveal that the sharing economy obstructs the entry of new industry players and creates a strong competition between the traditional commercial model and collaborative consumption. However, sharing economy contributes to people's high quality of life and savings. Consumers become the ultimate beneficiary when companies reduce their profit due to tight competition. To attract additional customers, companies must cut down their profit. Thus, the sharing economy plays an adjusted role in the healthy development of society.

Data from the report on the Chinese sharing economy in 2017, which was jointly issued by the sharing economy research center of state information and the sharing economy working committee of the Internet society of China 
(http://www.sohu.com/a/221294391_735021, accessed May 20, 2018), showed that the volume of trade in the sharing market accounted for about U\$6000 million, which increased by 47\% from 2016 Naturally, negative reports about the sharing economy emerged; these reports claim that sharing economy increased the unemployment rate in the long term, although increasing sharing economy transactions can promote economic development (Horton \& Zeckhauser, 2016). Yaraghiand Ravi (2017) argued that the global collaborative consumption has reached a new height, which profoundly impacts the popularity of part-time jobs. Sharing economy also changed the fabric of the social economy. Sundararajan (2016, p. 107-108) named it "uberisation of work," which is the definition of this new category of work, that is, these works do not run their own business and do not require full-time employment.

\subsection{Shared bikes and carbon dioxide emission}

\subsubsection{Global warming and carbon dioxide emission}

Economic loss due to global warming is estimated to reach as high as U\$ $1.2 \times 10^{10}$ annually. In addition tonatural factors, the main cause of global warming is human consumption of energy (BP oil disaster). The control of $\mathrm{CO}_{2}$ emissions and other greenhouse gases, such as nitrous oxides and sulfur oxide, facilitates the elimination of the adverse impact on economy and society.

Based on data from the Intergovernmental Panel on Climate Change, the greenhouse gases produced by city traffic accounted for $13 \%$ of the global total emissions, $30 \%-40 \%$ of which was $\mathrm{CO}_{2}$. The data released by China's National Bureau of Statistics show that the average growth rate of the number of cars in China has been $17 \%$ for the past 15 years. The rapid increase in automobile demand has accelerated the development of the automobile industry. However, such growth has resulted in the frequent occurrence of traffic congestion and hazy weather. Overcoming these problems is a common concern in the development of a city. The emergence of the sharing economy significantly impacts our mindset. That is, effective utilization of resources may solve traffic congestion and reduce $\mathrm{CO}_{2}$ emission.

\subsubsection{Development of shared bikes}

At present, citizens in China can select from several modes of transportation, such as public bikes, shared bikes, electric bikes (e-bikes), taxi, public transportation, and private cars. People are currently aware of the importance of health and environmental protection. 
Thus, many people select cycling as a physical exercise if their destination is near. Many studies have verified the physical benefits of biking, such as improvement in the transcription of telomere (telomere length is considered the body's anti-aging maker), maintenance of telomere length, the growth of important molecules in the body, acceleration of metabolism, and delayed aging.

Each bike has its own characteristics. Public bikes require stations for parking, whereas shared bikes do not. Moreover, shared bikes are equipped with Global Positioning System (GPS) to help riders navigate. Shared bikes can be parked nearly anywhere. An obvious characteristic of using shared bikes is that the registered users conveniently use their mobile phones to scan the Quick Response (QR) code on bikes to be able to use them. Once personal identity was verified by the GPS, the lock automatically opens, and the user can use the bike. From that point onward, the usage time is recorded by the application software. The unlocking process must not exceed 3s. Czech, Turoń, and Urbańczyk (2017) believed that the convenience provided by communication technology and interactivity boosts public interest on shared bikes. Also, the present mode was in agreed with the concept of fourth generation or shared micromobility described by Susan, et al. $(2014,2019)$. With the advancement of urbanization in China, population size grows in the cities. For example, 72 cities have populations that exceeded 1 million in 2015. The population in Shanghai, Beijing, Shenzhen, and Chongqing exceed 10 million. Naturally, the usage rate of shared bikes is high in densely populated cities.

\subsubsection{Green benefits from shared bikes}

The analysis from Shaheen, Guzman, and Zhang (2010) demonstrated the advantages of shared bikes, such as convenient journey, reduction of traffic congestion in cities, $\mathrm{CO}_{2}$ emission reduction, flexible mobility, and physical health benefits. The possible amount of the reduction in oil consumption and $\mathrm{CO}_{2}$ emissions in the United States was calculated by Higgins and Higgins (2005); these authors concluded that the reduction of gasoline demand is equivalent to $34.9 \%$ of the current domestic oil consumption, thus assuming that driving cars is substituted by cycling. The concomitant reduction of $\mathrm{CO}_{2}$ emissions will be approximately $10.9 \%$, relative to emissions in1990. Clearly, leading a healthy lifestyle (i.e., regular exercise with cycling) by giving up driving for short trips can simultaneously reduce oil consumption and protect the environment. 
Zahabi et al. (2016) emphasized that the accessibility of cycling infrastructure is positively linked to the shift from driving to cycling. Rojas-Rueda et al. (2016) assessed the health impacts of replacing car trips with cycling and confirmed that reducing car usage and increasing cycling in cities can bring health benefits for travelers and general citizens in the city. Caulfield et al. (2017) examined the usage patterns of a bike-sharing scheme in medium cities and found that short trips account for the majority. Moreover, in most cases, frequent trips have the shortest travel times, thereby suggesting that users have incorporated the scheme into their daily (or weekly) trips. Jain and Tiwari (2016) advised that driving a car is not the optimal choice in considering comprehension benefits, such as greenhouse emissions, energy consumption, and travel behavior, if the average distance of trips in cities is less than $5 \mathrm{~km}$; thus, these researchers recommended that developing non-motorized transport infrastructure must be prioritized, including the improvement of bike infrastructure, which can effectively reduce the risk of motor vehicle accidents. Rojas-Rueda, De Nazelle, and Teixidó (2012)studied the health impacts of active transportation in Europe and confirmed that active transportation policies can result in health benefits.

\subsubsection{Carbon dioxide emission and economy}

Panayotou (1993) first reported that the relationship between environmental quality and per capita income follow the environmental Kuznets curve (EKC), which is an inverse Ubend curve. Grossman and Krueger (1995) confirmed that the relationship between $\mathrm{CO}_{2}$ index and per capita income is consistent with the inverse U-shape curve. Martınez and Bengochea (2004) demonstrated an "N-shape" relationship between $\mathrm{CO}_{2}$ emission reduction and national economic development. Numerous authors have used the EKC hypothesis to test the relationship between carbon emissions and GDP in China (Jalil\& Mahmud, 2009, Shen et al. 2018). A report from Haliciogly (2009) reflected that $\mathrm{CO}_{2}$ emissions have different long-and short-term influences on GDP in developed countries. Narayan and Popp (2012) used the EKC hypothesis to analyze greenhouse gas emissions in 43 developed countries in accordance with the long-and short-run income elasticityfrom1980 to 2004; these authors concluded that the high income in developed countries motivates citizens' social responsibility of reducing carbon emissions. Notably, Lise and Van Montfort (2007) rejected the EKC hypothesis through the Engle-Granger co-integration approach in a study period from 1970 to 2002. Dogan, et al. (2017) stated that the EKC hypothesis has not been validated for OECD countries because the effects 
of levels of emission on the GDP are inconclusive. These studies provide valuable information, significant data on the amount of $\mathrm{CO}_{2}$ emission reduction from using shared bikes, and its few economic benefits.

\section{Data and methodology}

\subsection{Data collection}

A total of 6,428,186 raw data items about Mobike's performance from May 10-24, 2017 in Beijing, have been collected. The open data came from the Mobike Cup organized by the Mobike Company. The said competition enabled participants to predict the factors of customers' behavior for using Mobike in the future. Every piece of data including the information about user ID, bike ID, ordered time, departure location, and arrival location in geohash format (geographic location was encoded into a short string of digits and letters known as geohash) was recorded. So, in the following study, Mobike was selected, and user behavior and track of shared bike can be analyzed with Excel software. Given that the data in the periods selected came from similar weather conditions in Beijing, the effects of weather condition on trips would be ignored. The statistic variables include proportion of users, usage rate, and usage time of shared bikes. For quantitative analysis, the range of used data was restrained by the results of qualitative analysis and boundary conditions.

\subsection{Methods}

\subsubsection{Qualitative analysis}

According to the report, which was distributed by China academy of telecommunication research of MIIT (http://www.sohu.com/a/221294391_735021, Accessed May 31, 2018), 7.44 million tons of vehicle exhausts were reduced in 2017 considering the use of shared bikes. This amount is equivalent to $1 \%$ of the national gasoline output. Given that Mobike is the largest shared bike company in the world, it is extensively represented in different locations. In this process, many factors may

affect the benefits. Here, only some important factors, such as riding time or distance, proportion of users in the registered account, and usage rate of shared bike in different periods in a day, can be used in the qualitative analysis. Their values can be produced through Excel statistical software. For the distance, it may be estimated through heat maps (Fig.1 a and b) of the track of the bikes or the difference of ordered time of bike ID; for the proportion of users and the usage rate of shared bike in a day or a period, they can be acquired through statistics and analysis. In addition, some data from 
ArcGIS which are unrelated to Beijing must be excluded after decoding geohash into the GPS location. Of course, the prediction made with these data was based on normally urban traffic and healthy users. However, some hypotheses must be considered, including: (1) road of urban distract was not repaired or rebuilt,(2)climatic conditions were similar to the last year,(3) some unpredictable factors were not also considered,(4) difference of weekdays and weekends was ignored.

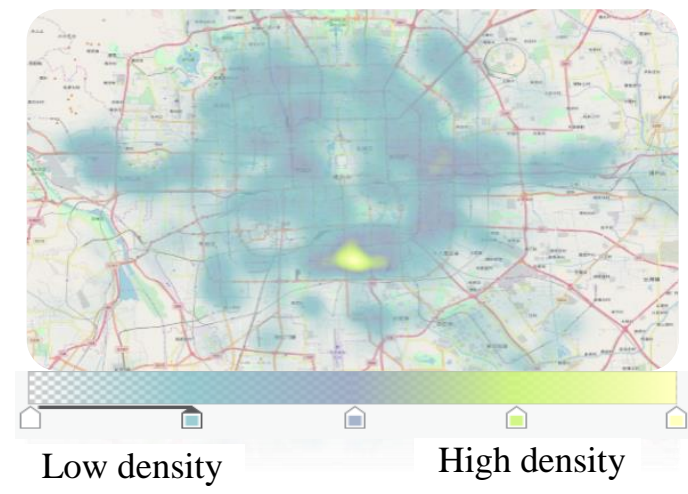

Fig. 1a Distribution of departure location of shared bikes

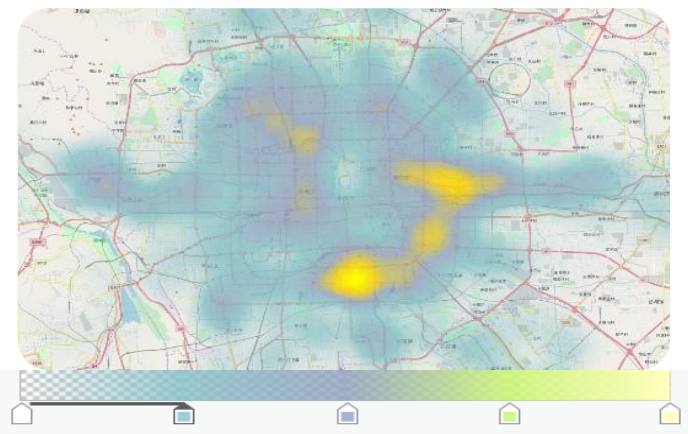

Fig. 1b Distribution of arrival place of shared bikes

\subsubsection{Quantitative method}

The usage behavior of users of shared bikes is closely related to the amount of $\mathrm{CO}_{2}$ emission reduction. Thus, the amount of $\mathrm{CO}_{2}$ emission reduction can be designed as an objective function. According to the influential extent of each variable on the usage of shared bike, three key factors will be considered in this study. With the data from shared bike in the designed scenario, a model of the amount of $\mathrm{CO}_{2}$ emission reduction was constructed through response surface method (RSM) and forecasted in the future. The RSM was first proposed by Box et al. (1950). It is an effective statistical tool for optimizing the influenced variables through the relationship expressed by functions between variables and respond values obtained through the fitting of a polynomial. The main variable can be obtained by analyzing the relationship of variables, variable and response values, and influence degree of these functions. RSM is an integration of mathematical and statistical techniques for modeling and analyzing problems with multiple variables that influence the objective. The process of optimization can be divided into six stages: (1) selection of independent variables and possible responses, (2) selection of experimental design strategy, (3) execution of experiments and obtaining results, (4) fitting the model equation to experimental data, (5) obtaining response graphs and verification of the model, (6) determination of optimal conditions. In order to evaluate 
the influence of operating parameters on $\mathrm{CO}_{2}$ emission, three main factors were chosen: proportion of users, riding distance, and usage rate of bikes. The scenario scheme to forecast $\mathrm{CO}_{2}$ emission is devised by combining Central Composite Design (CCD) with Box-Behnken Design (BBD), which are two widely used forms of RSM (Anna WitekKrowiak et al, 2014). A total of 30 experiments, which are produced after removing 5 repeated experiments from 20 experiments obtained by CCD and 15 experiments by BBD, were employed in this work. Analysis of variance was performed to determine the individual linear, quadratic and interaction regression coefficients using Minitab 14. The coefficient of determination $\left(\mathrm{R}^{2}\right)$ was used to estimate the fitness of the polynomial equation to the responses, and the significance of the dependent variables was statistically analyzed by computing the $F$ value at $p<0.05$. In addition, RSM is used to evaluate the mutual impacting extent of variables (Gholipour, Haghighat, and Meybodi, 2018) by focusing on $\mathrm{CO}_{2}$ emission reduction. After calculating the $\mathrm{CO}_{2}$ emission reduction from the usage of shared bikes, the equation to forecast the amount of $\mathrm{CO}_{2}$ emission reduction from shared bikes and economic contribution to related industries is constructed.

\section{Findings}

\subsection{Qualitative analysis of factors}

\subsubsection{Proportion of users}

Figure 2 illustrates the average number of times that users ordered the shared bike at different periods in a day from May 10-24, 2017.

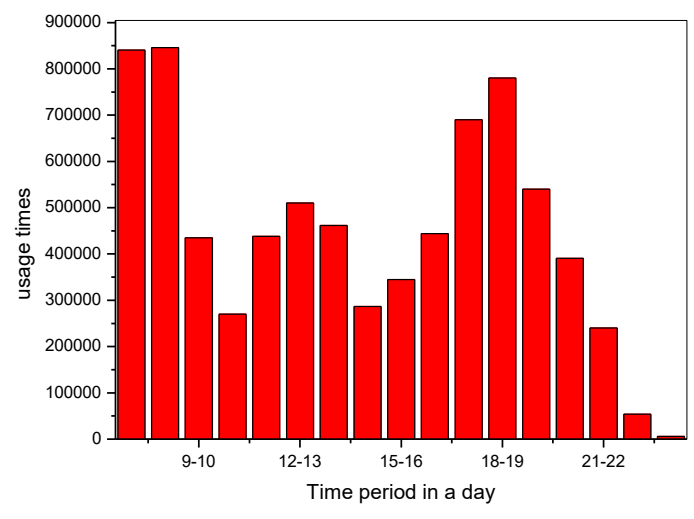

Fig. 2 Average orders for the shared bike in different time periods in a day

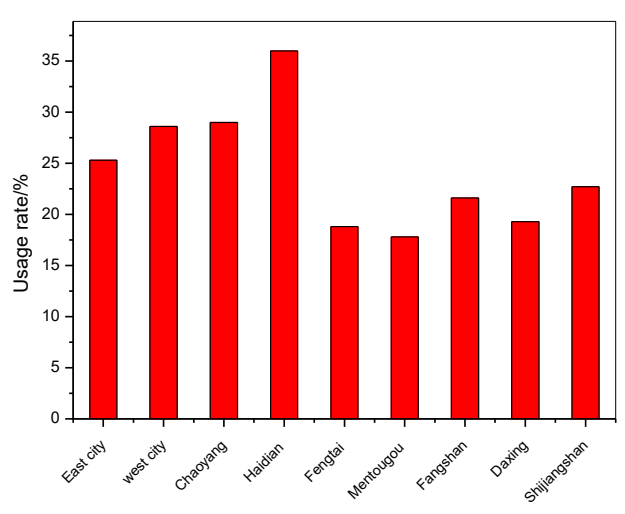

Fig.3 Usage rate for shared bike in main districts in Beijing

The total demand for shared bikes in a day's period takes an M-shaped curve. The number of orders peaks at 7-9 A.M. and 5-7 P.M.; these periods are the rush hours. These orders account for $40.16 \%$ of the total orders of a single day because some people likely select 
flexible vehicles, such as shared bikes, in traveling to work to avoid traffic congestion. The mean times reach nearly 150,000 in a day. This result is consistent with the report by El-Assi and Habib (2017) and Faghih-Imani, Eluru, and El-Geneidy(2014). Until the end of 2017, registered users have reached 12 million in Beijing. Clearly, 0.05\% of the lowest proportion in the registered accounts of shared bikes is found from 11 P.M. to 12 A.M., and the highest proportion is $7.05 \%$ from 7 A.M. to 9 A.M. The mean proportion is approximately $3.71 \%$. So, the proportion of users is in the range of $1 \%$ to $8 \%$. Interestingly, the highest number of orders in the afternoon constantly occurs after 7 P.M. despite most employees in Beijing going home at 5 P.M. This deviation is ascribed to the modern lifestyle of young people who prefer to eat in restaurants. Thus, redistributing bikes in the appropriate period is necessary to maximize the usage rate of bikes.

\subsubsection{Usage rate of shared bikes}

Figure 3 plots the mean usage rate for shared bikes from May 10-24, 2017, in different regions in Beijing. The highest usage rate for shared bikes occurred in Haidian district, which reached $36 \%$ given the many schools located in this region. In addition, the number of visitors was also much higher in Haidian than in other districts. The mean value is as high as $24.3 \%$. That is to say, the usage rate of shared bike of $15 \%$ to $25 \%$ was reasonable.

\subsubsection{Riding distance}

Based on the distribution and track, the riding distance was in the range from 1,000 $\mathrm{m}$ to 3,500 $\mathrm{m}$ for most people. However, $5 \mathrm{~km}$ of riding distance is also observed from the heat map (Fig.1a and 1b). Approximately 80\% users have implemented the "travel within $2.5 \mathrm{~km}$." User comments on the official Mobike website revealed that short-distance trips between bus and subway stations are the primary route. That is, the distance in the short trips from stations to homes or workplaces after a long travel is well filled by shared bikes. The development of shared bikes aims to solve such short trips. Shared bikes are frequently believed to be a powerful tool for solving this issue in China. In the process of quantitative analysis, the riding distance of $1 \mathrm{~km}$ to $5 \mathrm{~km}$ is selected.

\subsubsection{Influence of weekdays and weekends}

The statistical results from the database demonstrated a higher demand of approximately $43.6 \%$ for shared bikes $(284,000)$ during weekdays than during weekends $(160,000)$.One probable reason is that employees go to work on weekdays. Traffic control is another reason. In Beijing, some cars are prohibited on the road if their license plate number is restricted for that day. Thus, most users simply stay at home or use other vehicles during 
weekends. Notably, this discussion does not involve weather effects on shared bike usage rate, regardless if the weather is rainy, windy, or chilly.

\subsection{Quantitative analysis}

The amount of $\mathrm{CO}_{2}$ emission reduction and industrial chain profits caused by using shared bikes were separately analyzed in this part.

\subsubsection{Amount of $\mathrm{CO}_{2}$ emission reduction}

\subsubsection{Construction of regression equation}

Based on the discussion in Section 3.1, the main variables affecting the income of the shared bike company are similar to that of $\mathrm{CO}_{2}$ emission reduction. At present, the resident population in Beijing has reached 21.73 million. In addition, approximately 8-9 million migrants live in the capital. The population density in Beijing is 1,341 people $/ \mathrm{km}^{2}$. The number of shared bikes launched in the market is 2.2 million. To achieve $\mathrm{CO}_{2}$ emission reduction by using shared bikes, some reasonable assumptions may be proposed in accordance with the presented data. Here, factors, such as proportion of users, riding distance, and usage rate of bikes, act as independent variables $\mathrm{x}_{1}, \mathrm{x}_{2}$, and $\mathrm{x}_{3}$, respectively. According to online statistics and the discussion above, the level of these variables is listed in Table 1. In this process, the amount of $\mathrm{CO}_{2}$ emission is defined as response value $Y_{1}$. The test scheme and results based on the Box-Behnken method from Minitab software are summarized in Table 2.

Table 1. Experimental ranges and levels of the independent test variables

\begin{tabular}{lccccc}
\hline \multicolumn{1}{c}{ Variables } & \multicolumn{5}{c}{ Ranges and levels } \\
\cline { 2 - 6 } & -2 & -1 & 0 & +1 & +2 \\
\hline Proportion of user $\left(\mathrm{x}_{1}, \%\right)$ & 1 & 3 & 4 & 5 & 8 \\
Riding distance $\left(\mathrm{x}_{2}, \mathrm{~km}\right)$ & 1 & 2 & 3 & 4 & 5 \\
Usage rate of shared bikes $\left(\mathrm{x}_{3}, \%\right)$ & 10 & 15 & 18 & 20 & 25 \\
\hline
\end{tabular}

Generally, $2.23 \mathrm{~kg}$ of $\mathrm{CO}_{2}$ is released for every liter (L) of gasoline consumed by cars. Motor vehicles normally consume an average of $8 \mathrm{~L}$ of gasoline per $100 \mathrm{~km}$. Thus, the amount of $\mathrm{CO}_{2}$ emission $(Y)$ in a day can be expressed in Equation (1) as follows:

$$
\mathrm{Y}_{1}\left(\mathrm{CO}_{2}\right)=1.2 \times 10^{7} \times 2.2 \times 10^{6} \times 2.23 \times 8 \times \mathrm{x}_{1} \mathrm{x}_{2} \mathrm{x}_{3} / 100(\mathrm{~kg})=4.70976 \times 10^{8} \mathrm{x}_{1} \mathrm{x}_{2} \mathrm{x}_{3}(\mathrm{~kg})
$$


where $1.2 \times 10^{7}$ represents the number of registered users, and $2.2 \times 10^{6}$ is the number of shared bike launched in the market. The results of the $Y$ value at different scenarios are listed in Table 2.

Table 2. Independent variables and corresponding response values

\begin{tabular}{cccccccccc}
\hline Run & $\mathrm{X}_{1}$ & $\mathrm{X}_{2}$ & $\mathrm{X}_{3}$ & $\mathrm{Y}_{1 \times 10^{7}(\mathrm{~kg})}$ & $\mathrm{Run}$ & $\mathrm{X}_{1}$ & $\mathrm{X}_{2}$ & $\mathrm{X}_{3}$ & $\mathrm{Y}_{1 \times 10^{7}}(\mathrm{~kg})$ \\
\hline 1 & 5 & 5 & 10 & 1.18 & 16 & 3 & 3 & 10 & 0.42 \\
2 & 5 & 1 & 15 & 0.35 & 17 & 3 & 4 & 18 & 1.02 \\
3 & 5 & 4 & 15 & 1.41 & 18 & 4 & 5 & 25 & 2.36 \\
4 & 5 & 3 & 10 & 0.71 & 19 & 8 & 3 & 15 & 1.70 \\
5 & 5 & 5 & 25 & $\mathbf{2 . 9 4}$ & 20 & 3 & 4 & 15 & 0.85 \\
6 & 5 & 4 & 25 & 2.36 & 21 & 4 & 1 & 25 & 0.47 \\
7 & 8 & 1 & 15 & 0.57 & 22 & 3 & 5 & 10 & 0.71 \\
8 & 3 & 1 & 10 & $\mathbf{0 . 1 4}$ & 23 & 5 & 4 & 15 & 1.41 \\
9 & 8 & 4 & 10 & 1.51 & 24 & 8 & 5 & 15 & 2.83 \\
10 & 3 & 3 & 20 & 0.85 & 25 & 3 & 4 & 15 & 0.85 \\
11 & 8 & 3 & 15 & 1.70 & 26 & 4 & 5 & 25 & 2.36 \\
12 & 4 & 5 & 15 & 1.41 & 27 & 8 & 4 & 15 & 2.26 \\
13 & 3 & 1 & 25 & 0.35 & 28 & 4 & 3 & 18 & 1.02 \\
14 & 8 & 2 & 15 & 1.13 & 29 & 3 & 5 & 10 & 0.71 \\
15 & 1 & 3 & 15 & 0.21 & 30 & 3 & 4 & 10 & 0.57 \\
\hline
\end{tabular}

The amount of $\mathrm{CO}_{2}$ emission reduction from using shared bikes is at least $\mathbf{1 . 4 \times 1 0 ^ { 6 }}(\mathrm{kg})$ in a day when the proportion of users $\left(x_{1}\right)$, riding distance $\left(x_{2}\right)$, and usage rate of bikes $\left(x_{3}\right)$ are $5 \%, 25 \%$, and $10 \%$, correspondingly. The maximum amount is $\mathbf{2 . 9} \times \mathbf{1 0}^{\mathbf{7}}(\mathrm{kg})$. Apparently, the number of shared bikes in the market and population size significantly influences the amount of $\mathrm{CO}_{2}$ emission reduction.

\subsubsection{Influential extent of the variables}

In consideration of the interactive influence on $Y_{1}\left(\mathrm{CO}_{2}\right)$ among variables $x_{1} x_{2}, x_{1} x_{3}$, and $x_{2} x_{3}$, the regression equation of the respective variable on the contribution of $\mathrm{CO}_{2}$ emissionreduction $\left(Y_{2}\right)$ can be obtained through Minitab 14 software. The operating 
steps of Minitab were as follows: in turn, Stat, DOE, Response Surface, Analysis Response Surface Design, Continuous variables $\mathrm{x}_{1}, \mathrm{x}_{2}$, and $\mathrm{x}_{3}$ which had been designed to $\mathrm{C}_{1}, \mathrm{C}_{2}$ and $\mathrm{C}_{3}$ (from low to high), and Response variables $\mathrm{Y}_{1}$ were selected and then confirmed. The regression equation (2) in Uncoded Units is obtained in the below.

$$
\begin{aligned}
\mathrm{Y}_{2}= & \left(95.9-26.93 \mathrm{X}_{1}-24.05 \mathrm{X}_{2}-6.885 \mathrm{X}_{3}+0.085 \mathrm{X}_{1}{ }^{2}-0.055 \mathrm{X}_{2}^{2}+0.0197 \mathrm{X}_{3}{ }^{2}\right. \\
& \left.+6.881 \mathrm{X}_{1} \cdot \mathrm{X}_{2}+1.775 \mathrm{X}_{1} \cdot \mathrm{X}_{3}+1.7128 \mathrm{X}_{2} \cdot \mathrm{X}_{3}\right) \times 10^{5}(\mathrm{~kg}) .
\end{aligned}
$$

To verify whether equation (2) is reasonable, the regression coefficients were examined through $t$-test method. The test results are summarized in Table 3.

Table 3. Estimated values of the partial regression coefficients for the model

\begin{tabular}{ccccc}
\hline Term & Effect & Coefficient $^{*}$ & T-value & P-value \\
\hline constant & - & 1.1195 & 90.57 & 0 \\
$\mathrm{X}_{1}$ & 1.7886 & 0.8943 & 56.19 & 0 \\
$\mathrm{X}_{2}$ & 1.4624 & 0.7312 & 95.74 & 0 \\
$\mathrm{X}_{3}$ & 1.0397 & 0.5198 & 55.73 & 0 \\
$\mathrm{X}_{1}{ }^{2}$ & 0.0208 & 0.0104 & 0.58 & 0.569 \\
$\mathrm{X}_{2}{ }^{2}$ & -0.0044 & -0.0022 & -0.17 & 0.87 \\
$\mathrm{X}_{3}{ }^{2}$ & 0.0221 & 0.0111 & 0.85 & 0.406 \\
$\mathrm{X}_{1} \cdot \mathrm{X}_{2}$ & 0.9633 & 0.4817 & 31.99 & 0.000 \\
$\mathrm{X}_{1} \cdot \mathrm{X}_{3}$ & 0.9321 & 0.466 & 16.89 & 0.000 \\
$\mathrm{X}_{2} \cdot \mathrm{X}_{3}$ & 0.5138 & 0.2569 & 25.75 & 0.000 \\
\hline
\end{tabular}

*coded.

Typically, a small $\mathrm{p}$ value denotes a significant test result. The significance test of the coefficients of regression Equation (2) is presented in Table 3, in which the linear and interactive items are significant, whereas the quadratic terms are not. So, the regression fitting equation (3) in Uncoded Units is obtained after the variables of all the square terms were removed as follows.

$$
\begin{aligned}
\mathrm{Y}_{3}= & \left(0.8969-0.2616 \mathrm{x}_{1}-0.2453 \mathrm{x}_{2}-0.06198 \mathrm{x}_{3}+0.06916 \mathrm{x}_{1} \cdot \mathrm{x}_{2}+0.017726 \mathrm{x}_{1} \cdot \mathrm{x}_{3}\right. \\
& \left.+0.017114 \mathrm{x}_{2} \cdot \mathrm{x}_{3}\right) \times 10^{7}(\mathrm{~kg}) .
\end{aligned}
$$

The results from the variance analysis for each item in equation (3) are summarized in Table 4. In this table, the $F$ value of the regression equation is equal to 4,508.11.This value is far greater than 8.94 of the $\mathrm{F}_{0.05}(6,3)$ value when the $\mathrm{P}$ value is 0 , which is less than 0.05 . In Table 4 , the determination coefficient $R^{2}$ of $99.92 \%$ is also obtained, thereby 
indicating that equation (2) has a significant fitting degree and can be used for theoretical analysis and prediction.

Table 4. Analysis of variance and coefficient of association of the model

\begin{tabular}{lrrrrr}
\hline \multicolumn{1}{c}{$\begin{array}{c}\text { Source of } \\
\text { variance }\end{array}$} & $\begin{array}{c}\text { Degree } \\
\text { freedom }\end{array}$ & $\begin{array}{c}\text { Stdev } \\
\text { square }\end{array}$ & $\begin{array}{c}\text { Mean } \\
\text { square }\end{array}$ & $\boldsymbol{F}$ & $\boldsymbol{P}$ \\
\hline Regression equation & 6 & 18.1952 & 3.03255 & $4,508.11$ & 0.000 \\
Linear & 3 & 11.8003 & 3.93342 & $5,847.35$ & 0.000 \\
$\mathrm{x}_{1}$ & 1 & 2.9268 & 2.92684 & $4,350.98$ & 0.000 \\
$\mathrm{x}_{2}$ & 1 & 7.0035 & 7.00352 & $10,411.3$ & 0.000 \\
$\mathrm{x}_{3}$ & 1 & 2.608 & 2.60805 & $3,877.08$ & 0.000 \\
$2-$ Way interaction & 3 & 1.5343 & 0.51142 & 760.27 & 0.000 \\
$\mathrm{x}_{1} \mathrm{x}_{2}$ & 1 & 0.7931 & 0.79313 & $1,179.05$ & 0.000 \\
$\mathrm{x}_{1} \mathrm{x}_{3}$ & 1 & 0.2162 & 0.21606 & 321.19 & 0.000 \\
$\mathrm{x}_{2} \mathrm{x}_{3}$ & 1 & 0.5027 & 0.50272 & 747.34 & \\
\hline
\end{tabular}

To evaluate the impacted extent of each variable on $Y$, the effects of the main variables of linear items on $Y_{l}$ are depicted in Fig 4 .

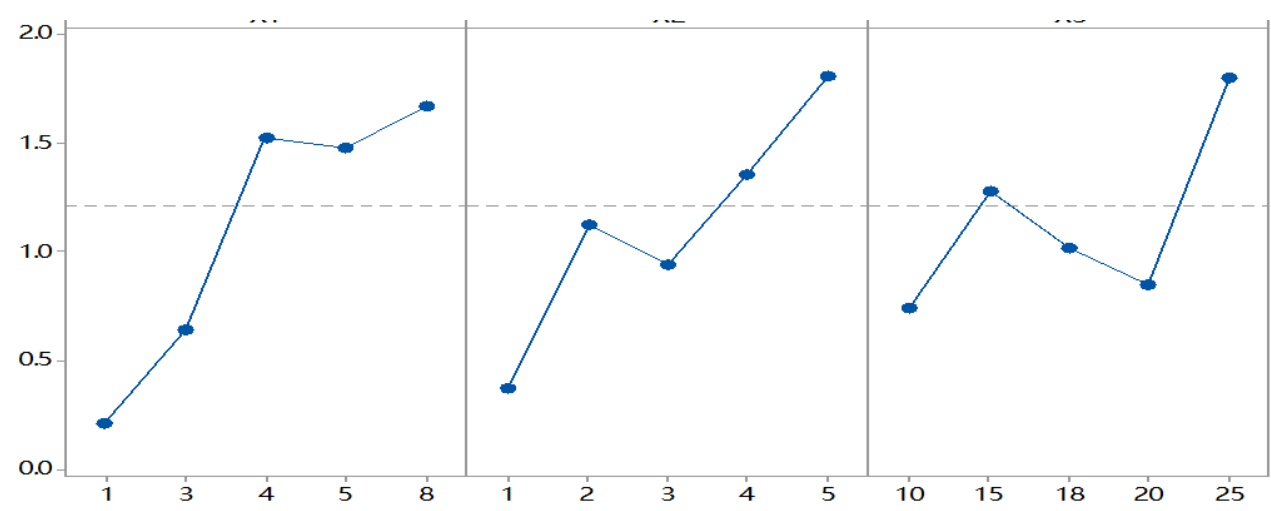

Fig. 4 Effects of the main variables on $Y_{1}$ of $\mathrm{CO}_{2}$ emission reduction $\left(\times 10^{7} / \mathrm{kg}\right)$

In Fig. 4, each variable, namely, proportion of user, riding distance, and usage rate of bike notably influence their difference between the mean value and total average (dashed horizontal line). A huge difference indicates a significant influence. This finding is consistent with the results of the coefficient $t$-test method. The order of the influencing extent is as follows: riding distance >proportion of registered users > usage rate of shared bikes. 


\subsubsection{Forecast of $\mathrm{CO}_{2}$ emission reduction}

Given climate change, some days were rainy (amount of precipitation ranged from $10-25 \mathrm{~mm}$ in $24 \mathrm{~h})$, windy $(\geq 4$ grade $)$, extremely hot $\left(\geq 32^{\circ} \mathrm{C}\right)$, or cold $\left(<-5^{\circ} \mathrm{C}\right)$. Thus, using shared bikes on such days may be unsuitable. The pollutant standard index also exceeds 150 on some days, thereby deeming the use of shared bikes was not ideal. Based on this classification, weather conditions in Beijing throughout 2017 (https://15tianqi.cn/beijing12yuetianqil, Accessed May 31, 2018; http://www.sohu.com/a/213881300_391266, Accessed May 31, 2018;) are listed in Table 5. Clearly, 268 days may be suitable for users to select cycling. Thus, $\mathrm{CO}_{2}$ emission reduction may have reached $3.75 \times 10^{8}(\mathrm{~kg})-7.87 \times 10^{9}(\mathrm{~kg})$. only in Beijing in 2017.

Table 5. Statistics of the weather condition in Beijing, China, in 2017

\begin{tabular}{lllllll}
\hline Condition & Hazy & Cold & Hot & Moderate rain & Windy & Good \\
\hline Days & 3 & 35 & 22 & 10 & 27 & 268 \\
\hline
\end{tabular}

As a comparison, economic benefit generated from $\mathrm{CO}_{2}$ emission reduction given the use of shared bikes can be estimated in accordance with the relationship between the amount of $\mathrm{CO}_{2}$ emission and the consumption of gasoline by cars. Here, the average cost of gasoline per $\mathrm{L}$ is assumed to be 7.00 yuan (RMB). The benefit from $\mathrm{CO}_{2}$ emission reduction is $7 Y_{1} / 2.23=3.139 Y_{1}(\mathrm{RMB})$. That is, the value ranges between $4.4 \times 10^{8}$ and $9.23 \times 10^{8}(\mathrm{RMB})$. Therefore, the economic effect of using shared bikes is considerable.

\subsection{Problems}

Shared bikes play a positive role in public transportation and in improving the environment. To encourage people to use shared bikes, making the bikes conveniently available, comfortable, and safe is necessary. Therefore, many servicemen must be employed for redistribution, repair, and recovery of discarded bikes. However, such work is challenging due to the extensive scatterness and deliberate destruction. Clearly, controlling maintenance cost and preventing man-made sabotage will significantly reduce operating costs. Evidently, if the local government provides support for shared bike companies, then the sustainability of shared bike companies will be achieved. An example of government support is the establishment of law for timely punishing people who 
deliberately destroy shared bikes. Therefore, man-made sabotage will be effectively avoided and the safety of the company will be assured.

\section{Conclusions}

Cycling is not only an easy and low-cost mode of transportation but also has other benefits, such as reducing pollution, greenhouse gases, noise, and traffic congestion. The qualitative results verified that the usage rate for shared bikes is higher on weekdays than on weekends. This variance is due to numerous employees who travel from their homes to their workplaces. Districts near the downtown and business center and with a high population density have a high usage rate for shared bikes. The redistribution of shared bikes in some places or some periods, such as in the morning and evening, is necessary to balance shared bikes' temporary shortage, which occurs randomly.

Based on the influential degree of each variable on $\mathrm{CO}_{2}$ emission reduction and economic benefits caused by the usage rate of shared bikes, the model that reflects their relationship between the objective and variables was constructed through the RSM. The regression fitting equation on the respective variable to the contribution of $\mathrm{CO}_{2}$ reduction emission is expressed as follows: $Y=\left(0.8969-0.2616 \mathrm{x}_{1}-0.2453 \mathrm{x}_{2}-0.06198\right.$ $\left.\mathrm{x}_{3}+0.06916 \mathrm{x}_{1} \cdot \mathrm{x}_{2}+0.017726 \mathrm{x}_{1} \cdot \mathrm{x}_{3}+0.017114 \mathrm{x}_{2} \cdot \mathrm{x}_{3}\right) \times 10^{7}(\mathrm{~kg})$, where $Y$ is the maximum value when the proportion of users, riding distance, and usage rate of bikes are $5 \%, 5 \%$, and $25 \%$, respectively. The amount of $\mathrm{CO}_{2}$ emission reduction is in the range of $3.75 \times 10^{8}(\mathrm{~kg})$ and $7.87 \times 10^{9}(\mathrm{~kg})$ in 2017 . The benefit can reach at least $4.4 \times 10^{8}$ (RMB) in a day. The influencing extent of factors on $\mathrm{CO}_{2}$ emission reduction is in the following order: riding distance > proportion of registered users > usage rate of shared bikes. This study provides a comprehensive cognition for the usage of shared bikes through data tests and theoretical analysis. These tests will help government policymakers and enterprise managers design an environmentally sustainable scheme and drive the rapid and healthy development of the economy.

\section{Reference}

Anna Witek-Krowiak, Katarzyna Chojnacka, Daria Podstawczyk, Anna Dawiec, Karol Pokomed. 2014. Application of response surface methodology and artificial neural network methods in modelling and optimization of biosorption process, Bioresource 
Technology 160:150-160.

Caulfield, B., O'Mahony, M., Brazil, W., \& Weldon, P. (2017). Examining usage patterns of a bike-sharing scheme in a medium sized city. Transportation research part A: policy and practice, 100, 152-161.

Chen J.Y. (2018) Technologies of Control, Communication, and Calculation: Taxi Drivers' Labour in the Platform Economy. (Moore P., Upchurch M., Whittaker X., Ed.). Humans and Machines at Work. Dynamics of Virtual Work. Palgrave Macmillan, Cham Czech, P., Turoń, K., \&Urbańczyk, R. (2017). Bike-Sharing as an Element of Integrated Urban Transport System. In Scientific and Technical Conference Transport Systems Theory and Practice, 103-111.

Dogan, E., Seker, F., \& Bulbul, S. (2017). Investigating the impacts of energy consumption, real GDP, tourism and trade on $\mathrm{CO}_{2}$ emissions by accounting for crosssectional dependence: A panel study of OECD countries. Current Issues in Tourism, 20(16), 1701-1719.

El-Assi, W., Mahmoud, M. S., \& Habib, K. N. (2017). Effects of built environment and weather on bike sharing demand: a station level analysis of commercial bike sharing in Toronto. Transportation, 44(3), 589-613.

Gholipour, M., Haghighat, A. T., Meybodi, M. R. (2018). Congestion avoidance in cognitive wireless sensor networks using TOPSIS and response surface methodology, Telecommunication Systems, 67(3):519-537.

Grossman, G. M., \& Krueger, A. B. (1995). Economic growth and the environment. The quarterly journal of economics, 110(2), 353-377.

Haliciogly, F. (2009). An econometric study of $\mathrm{CO}_{2}$ emissions, energy consumption, income and foreign trade in Turkey. Energy Policy, 37(3), 1156-1164.

Hamari, J., Sjöklint, M. \& Ukkonen, A. (2016). The sharing economy: Why people participate in collaborative consumption. Journal of the Association for Information Science and Technology, 67(9), 2047-2059.

Heinrichs, H. (2013). Sharing Economy: A Potential New Pathway to Sustainability. GAIA: Ecological Perspectives for Science \& Society, 22(4), 228-231.

Higgins, P. A., \& Higgins, M. (2005). A healthy reduction in oil consumption and carbon emissions. Energy Policy, 33(1), 1-4.

Horton, J. J. \& Zeckhauser, R. J. (2016). Owning, Using and Renting: Some Simple Economics of the" Sharing Economy"(No. w22029). National Bureau of Economic Research. 
Jain, D. \& Tiwari, G. (2016). How the present would have looked like? Impact of nonmotorized transport and public transport infrastructure on travel behavior, energy consumption and $\mathrm{CO}_{2}$ emissions-Delhi, Pune and Patna. Sustainable Cities and Society, $22,1-10$.

Jalil, A. \& Mahmud, S. F. (2009). Environment Kuznets curve for $\mathrm{CO}_{2}$ emissions: a cointegration analysis for China. Energy Policy, 37(12), 5167-5172.

Lise, W. \& Van Montfort, K. (2007). Energy consumption and GDP in Turkey: Is there a co-integration relationship? Energy Economics, 29(6), 1166-1178.

Matofska, B. (2014). What is the sharing economy? Retrieved from http://www.thepeoplewhoshare.com/blog/what-is-the-sharing-economy/

Martınez-Zarzoso, I. \& Bengochea-Morancho, A. (2004). Pooled mean group estimation of an environmental Kuznets curve for $\mathrm{CO}_{2}$. Economics Letters, 82(1), 121-126.

Narayan, P. K. \& Popp, S. (2012). The energy consumption-real GDP nexus revisited: Empirical evidence from 93 countries. Economic Modelling, 29(2), 303-308.

Panayotou, T. (1993) Empirical tests and policy analysis of environmental degradation at different stages of economic development. Working Paper WP238, Technology and Employment Programme, International Labor Office, Geneva.

Ruggles, R. (1998). The state of the notion: knowledge management in practice. California management review, 40(3), 80-89.

Rojas-Rueda, D., De Nazelle, A., Teixidó, O., \&Nieuwenhuijsen, M. J. (2012). Replacing car trips by increasing bike and public transport in the greater Barcelona metropolitan area: a health impact assessment study. Environment international, 49, 100-109.

Report: a. Influence of shared bike on economy and society in 2017, available at http://www.sohu.com/a/221294391_735021; b.

Rojas-Rueda, D., De Nazelle, A., Andersen, Z. J., Braun-Fahrländer, C., Bruha, J., Bruhova-Foltynova, H., \& Nieuwenhuijsen, M. J. (2016). Health impacts of active transportation in Europe. PloS one, 11(3),7-11.

Shaheen, S., Guzman, S., \& Zhang, H. (2010). Bikesharing in Europe, the Americas, and Asia: past, present, and future. Transportation Research Record: Journal of the Transportation Research Board, (2143), 159-167.

Sundararajan, A. (2016). The sharing economy: The end of employment and the rise of crowd-based capitalism. (Massachusetts, Ed.). United States of America: Sabon LT Std. (Original work published 2016) 
Susan A Shaheen, Elliot W Martin, Nelson D Chan, Adam P Cohen, Mike Pogodzinski.(2014). Public bikesharing in North America during a period of rapid expansion: understanding business models, industry trends and user impacts. Mineta Transportation Institute, MTI Report,12-29.

Shaheen Susan, Cohen Adam. (2019). Shared micromoblity policy toolkit: docked and dockless bike and scooter sharing. Available at https://escholarship.org/uc/item/00k897b5

Wang, Y. (2017). Promoting Sustainable Consumption Behaviors: The Impacts of Environmental Attitudes and Governance in a Cross-National Context. Environment and Behavior, 49(10), 1128-1155

Xiong, S. (2017). An Internet-based short-distance travel solution in China: case: Mobike Technology Co, Ltd.

Yaraghi, N., \& Ravi, S. (2017). The current and future state of the sharing economy, Available at SSRN 3041207.

Zahabi, S. A. H., Chang, A., Miranda-Moreno, L. F., \& Patterson, Z. (2016). Exploring the link between the neighborhood typologies, bike infrastructure and commuting cycling over time and the potential impact on commuter GHG emissions. Transportation research part D: transport and environment, 47, 89-103.

Zervas, G., Proserpio, D., \& Byers, J. W. (2017). The rise of the sharing economy: Estimating the impact of Airbnb on the hotel industry. Journal of marketing research, $54(5), 687-705$.

Zhou, D. \& Lo, V. (2004). Cluster computing on the fly: resource discovery in a cycle sharing peer-to-peer system. Cluster Computing and the Grid. IEEE International Symposium, 66-73. 